\title{
Multiplicity of Active-Site in Heterogeneous Ziegler-Natta Catalyst and Its Correlation with Polymer Microstructure
}

\author{
A. T. M. Kamrul Hasan \\ Department of Applied Chemistry and Chemical Engineering Faculty of Engineering, \\ University of Rajshahi, Bangladesh
}

\begin{abstract}
Multiplicity of active-site in heterogeneous Ziegler-Natta catalysts and its correlation with polymer microstructure was studied through the surface structure analysis of catalyst by computer simulation of X-ray Photoelectron Spectroscopy (XPS) data and microstructure investigation of polypropylene chains based on the deconvolution of the molecular weight distribution curves by multiple Flory most probable distributions using Gel Permeation Chromatography (GPC) method. The number and relative intensities of these peaks were found correlated to the distribution of multiple active sites. In this investigation, four individual categories of active sites were identified, each of which yields polypropylene with unique properties of molecular weight and chain structure different from other active sites. The reason of the multiplicity of active sites was determined by the presence of different locations of surface titanium species coordinated with other surface atoms or molecules. These different surface complexes of active species determine the multiple active site nature of catalyst which replicates the microtacticity, molecular weight and chain microstructure distribution of polymer.
\end{abstract}

Keywords: Ziegler-Natta catalyst, Multiple active sites, Flory components, Computer simulation, Deconvolution, MWD.

\section{Introduction}

Since the discovery, Ziegler-Natta catalysts have been developed through several generations by the introduction of support materials $\left(\mathrm{MgCl}_{2}\right)$ and various electron donors to improve the catalytic performance relating to the activity and isospecificity of active sites, respectively. The successive development highly contributed to the progress of polyolefin industry made the catalyst systems complicated. In order to understand the interaction among the multiple catalytic components, research efforts (Terano et al., 2001) have been going on for a number of decades. Thus, many aspects regarding the origin of the multiplicity of active sites and the specific stereochemical roles of catalytic components such as cocatalysts, support materials, electron donors are still open for discussion (Galli et al., 1984). Various stereospecific active sites models namely, monometallic, bimetallic, three-sites and modified three-sites have been proposed by the researchers (Corradini et al., 1992; Corradini et al., 1993; Corradini et al., 1994). Many scientists are still trying to acquire information concerning the multiple nature of the active sites, the origin of isospecificty and the mechanism of stereospecific propylene polymerization (Busico et al., 2001).

We gathered a basic understanding (Hasan et al., 2005) concerning the isospecific nature of active sites on $\mathrm{TiCl}_{3}$ based catalysts from catalyst preparation and microstructure analysis of polypropylene (PP) produced. It was reported (Fan et al., 2003) that the molecular weight distribution (MWD) of polymer is strongly influenced by the polymerization conditions such as temperature, reaction time and types of cocatalyst. Moreover, four types of active centers were identified. The multiple nature of active sites was expected to be relating not only to the microstructure analysis of the PP but also correlating with the catalyst surface structure. In this work, X-ray Photoelectron Spectroscopy (XPS) was applied to characterize the catalyst and Gel Permeation Chrom atography (GPC) was applied for microstructure analysis through molecular weight distribution (MWD) of polymer chains. Heterogeneous Ziegler-Natta catalysts usually contain several types of active centers which differ one from another, as a result, most polymers produced with these catalysts provide much broader MWDs. Resolution of the MWD chromatograms into components was developed over several decades (Kissin et al., 1995) with nolinear, least-square computer programs. Two simplest MWD function are referred to as Schuzl-Flory distribution functions.

To determine whether the Flory component resolution procedure, which is easily applied to polymers with narrow MWDs can be dependably used to analyze polymers with broader MWDs, number of Flory components and their best

*Corresponding author. E-mail: alishaabir@yahoo.com 
fitting into the whole GPC curve are the most reasonable approach. The ability to identify Flory components in a GPC curve of a polymer with a broad MWD has only a limited value by itself (Kissin et al., 1995). Thus, the simulation has two goals: to identify the most reasonable approaches in finding the number of Flory components constituting a given GPC curve and to determine whether the computer program finds the real Flory components in complex GPC curves. When, during the peak-fitting procedure, the number of the Flory components is set the same as in the simulation, the computer program easily finds all correct values. If the number of Flory component is deliberately set at a lower or higher than their actual numbers in the simulated GPC curve (e.g. two instead of three or three instead of two), the quality of the fit will always be poor. All such situations can be easily identified and the number of the Flory components can be subsequently adjusted to achieve the better fit of calculated GPC curve through computer simulation. Based on the various active sites models and present findings, some plausible structures of the surface active site species were designated. Formation and transformation of such active species were duly included in design in order to explore the origin of multiplicity of active sites in the heterogeneous Ziegler-Natta catalysis.

\section{Materials and Methods}

\section{Raw materials}

Research grade propylene (Chisso Corp.) was used without further purification. Anhydrous AA- $\mathrm{TiCl}_{3}$ was supplied by Toho Titanium Co. Ltd. Molecular sieves 4A and molecular sieves 13X (Wako Pure Chemical Industries, Ltd.) were used as moisture scavengers for solvent purification. Heptane and toluene (Wako Pure Chemical Industries Ltd.) solvents were purified by passing through molecular sieves $13 \mathrm{X}$ column. Triethylaluminum (TEA) and diethylaluminumchloride (DEAC) (Tosoh Akzo Corp.) and nitrogen (Uno Sanso Corp.) were used without purification. TEA and DEAC were used after dissolving in toluene solvent.

\section{Catalyst preparation}

Wet ground (WG) processing of AA- $\mathrm{TiCl}_{3}$ catalyst was performed by milling 36 grams of supplied catalyst in a ball mill with $200 \mathrm{ml}$ heptane. The grinding of catalyst was carried out in a $1.2 \mathrm{~L}$ stainless steel pot containing 55 balls each of $25 \mathrm{~mm}$ diameter for $30 \mathrm{~h}$ at room temperature. This processed catalyst was obtained as heptane slurry. The entire process was performed under nitrogen atmosphere. Titanium content in the catalyst slurry was determined by the redox titration method. The catalyst slurry was then kept in a threenecked round-bottomed flask equipped with a magnetic chip under nitrogen atmosphere.

\section{Surface characterization of the catalyst}

The ultra high vacuum (UHV) chamber used in this study was equipped with a sputter ion gun for surface cleaning, an $\mathrm{X}$-ray source and a double pass cylindrical mirror analyzer (CMA) with a coaxial electron gun for X-ray photoelectron spectroscopy (XPS). The XPS data of the catalyst was taken by Physical Electronics Perkin-Elmer (Model Phi-5600 ESCA) spectrometer with monochromated $\mathrm{Al} \mathrm{K}_{\alpha}$ radiation $(1486.6 \mathrm{eV})$ operated at $300 \mathrm{~W}$. It was carried out in a glove bag under nitrogen atmosphere. The sample holder was then put into a vacuum transfer vessel (Phi Model 04-110, PerkinElmer Co., Ltd.), which is connected to the sample introduction chamber of the XPS instrument. The sample was degassed up to $10^{-7}$ Torr. The main chamber vacuum was kept above $5 \times 10^{-9}$ Torr during XPS data acquisitions. A neutralizer was used to reduce the charging effect in order to obtain a better signal to noise ratio. All binding energies (BE) were referenced to the $\mathrm{Au} 4 \mathrm{f}_{7 / 2}$ peak at $84 \mathrm{eV}$ to correct for the charging effect during data acquisition.

\section{Computer simulation technique}

Multiplet fittings of the Ti $2 p$ XPS curves were carried out by the Gaussian-Lorentzian method to determine the mixed states of valences in all the samples. The binding energy (BE) and the full width at half maximum (FWHM) values from the Ti 2p XPS spectra was measured and used as criteria for identification of the oxidation state, distribution state and existing state of surface Ti species on catalyst surface. The XPS spectra of Ti $2 p$ in the following section have been background subtracted and deconvoluted into a series of synthetic peaks $(67 \%$ Gaussian and $33 \%$ Lorentzian; $\mathrm{FWHM}=2.3 \mathrm{eV}$ ) that represent the photoelectron emission from different oxidation states (Kim and Somorjai, 2000). The fitting for each curve was repeated to ensure a reproducible result.

\section{Propylene polymerization}

Polymerization experiments were carried out in a threenecked $300 \mathrm{ml}$ round-bottomed flask reactor equipped with a magnetic chip. After nitrogen purging and heating, successive introduction of heptane solvent, Al-alkyl cocatalyst, catalyst slurry and propylene monomer were done. The conditions for polymerization were maintained as: $2 \mathrm{mmol} \mathrm{Ti}$ (slurry $5.65 \mathrm{ml}$ ), Al/Ti molar ratio 3 , heptane volume $138.35 \mathrm{ml}$, cocatalyst $6 \mathrm{ml}$, total volume $150 \mathrm{ml}$, temperature $4^{\circ} \mathrm{C}$ and time $30 \mathrm{~min}$. Polymerization was allowed to stop by introducing ethanol-water after experimental time. The polymer slurry was kept into ethanol-water for $12 \mathrm{~h}$ with stirring. Then it was successively washed with deionized water, dried at room temperature, dissolved in orthodichlorobenzene (ODCB) with heating, and reprecipitated into ethanol-water 
and then followed by filtration and drying in the vacuum dryer at $6^{\circ} \mathrm{C}$ until a constant weight was obtained.

\section{Microstructure analysis of polymer}

The molecular weight (MW) and molecular weight distribution (MWD) of polypropylene samples produced were determined by gel permeation chromatography (GPC) method (GPC, Senshu SSc-7100) with polystyrenes gel columns (Tosoh TSK-GEL G3000HHR and TSK-GEL G5000HHR) at $14^{\circ} \mathrm{C}$ using o-dichlorobenzene (ODCB) as a solvent. MW was calculated with a universal calibration curve based on polystyrene standards with narrow MWDs using appropriate Mark-Houwink constants. The resolution of GPC curves as deconvolution into Flory components was performed with the MicroMath Scientific computer programs software.

Instantaneous MWD of polypropylene made with multiples type catalyst as a superposition of four individual Flory most probable MWDs were indicated by solid line of the whole polymer and by dotted lines of the polymers made on distinct active site types.

\section{Results and Discussion}

Typical XPS spectra, shown in Figure 1, describe $\mathrm{Ti}_{2 \mathrm{p}}$ region of (a) $\mathrm{AA}-\mathrm{TiCl}_{3}$, (b) AA-TiCl ${ }_{3} / \mathrm{DEAC}$ and (c) AA$\mathrm{TiCl}_{3}$ /TEA catalysts. The XPS data findings in terms of binding energy (BE), full width and half maximum (FWHM), oxidation states, and atomic percentage of surface titanium species are listed in Table I. The constituent atoms of the catalyst $(\mathrm{Cl}, \mathrm{Ti}, \mathrm{C}, \mathrm{Al})$ were observed on the XPS measurable surface, approximately $2 \mathrm{~nm}$ in depth. To investigate the states of the titanium species in details, an XPS narrow scan of the $\mathrm{Ti}_{2 \mathrm{p}}$ region was performed for each catalyst. The doublet at 458.5 and $464.6 \mathrm{eV}$ are reported to be due to the Ti $2 \mathrm{p}_{3 / 2}$ and Ti $2 \mathrm{p}_{1 / 2}$ photoelectrons from titanium atoms in it molecular states (Debuquoit et al., 1983; Debuquoit et al., 1987). One of the Ti-species at a higher binding energy is assigned to the lower coordinated titanium species $\mathrm{Ti}^{3+}$ (a) with higher coordination vacancies whereas another at a lower binding energy is considered to be the higher coordinated titanium species $\mathrm{Ti}^{3+}(\mathrm{b})$ with lower coordination vacancies (Terano et al., 1999). Shifts in BE have a contribution from both the oxidation state and the charge on the nearest neighbor atoms of the excited atom. The chemical shift and the FWHM of the $2 p_{3 / 2}$ peak in XPS analysis of Ziegler-Natta catalysts indicate the electron density of the titanium species, namely the oxidation state and its distribution, respectively (Terano et al., 1999). Therefore, the active sites with higher coordinated surface $\mathrm{Ti}^{3+}(\mathrm{b})$ species, which originated from the interaction with DEAC, show higher isospecificity. It is also considered that the highly active Alalkyl cocatalyst causes a drastic change in the coordination state of the titanium species, resulting in a decrease of the higher coordinated titanium species into lower coordination one. From the Table I, it can be seen that the value of the surface Ti atomic percentage with a higher coordination state is much higher in the case of DEAC than TEA.

The doublet at two different binding energies (split between two peaks with an intensity ratio of 2:1) is reported to be due to spin-orbit coupling effects in the final state of the emitted electron (Debuquoit et al., 1983; Debuquoit et al., 1987; Terano et al., 1999). Thus, the doublet shown in the XPS spectra is ascribed to the $2 \mathrm{p}_{3 / 2}$ and $2 \mathrm{p}_{1 / 2}$ photoelectrons from

Table I: The XPS data analyses from multiplet curve fitting of Ti $2 p$ spectra with XPS acquisition time from $10 \mathrm{~min}$ to $2 \mathrm{~h}$ of $\mathrm{AA}-\mathrm{TiCl}_{3}$ based catalysts.

\begin{tabular}{|c|c|c|c|c|}
\hline \multirow[t]{2}{*}{ Catalyst system } & \multicolumn{2}{|c|}{ Ti $2 p(3 / 2)$} & \multirow{2}{*}{$\begin{array}{c}\text { Ti oxidation } \\
\text { state }\end{array}$} & \multirow{2}{*}{$\begin{array}{c}\text { Atomic } \\
\text { percentage }\end{array}$} \\
\hline & $\mathrm{BE}(\mathrm{eV})$ & FWHM (eV) & & \\
\hline \multirow{2}{*}{ WG $\mathrm{AA}-\mathrm{TiCl}_{3}$} & 459.02 & 1.69 & $\mathrm{Ti}^{3+}(\mathrm{a})$ & 40.41 \\
\hline & 457.88 & 2.62 & $\mathrm{Ti}^{3+}(\mathrm{b})$ & 59.58 \\
\hline \multirow[b]{2}{*}{ WG AA-TiCl $3 / \mathrm{DEAC}$} & 458.77 & 1.67 & $\mathrm{Ti}^{3+}(\mathrm{a})$ & 58.14 \\
\hline & 457.52 & 1.82 & $\mathrm{Ti}^{3+}(\mathrm{b})$ & 41.87 \\
\hline \multirow{2}{*}{ WG AA-TiCl 3 /TEA } & 458.83 & 1.54 & $\mathrm{Ti}^{3+}(\mathrm{a})$ & 81.16 \\
\hline & 457.48 & 1.70 & $\mathrm{Ti}^{3+}(\mathrm{b})$ & 18.84 \\
\hline
\end{tabular}

(Ref.: Au 4f (4/3), $84 \mathrm{eV}$ )

$\mathrm{Ti}^{3+}(\mathrm{a})$ : low coordinated

$\mathrm{Ti}^{3+}(\mathrm{b})$ : high coordinated 
titanium atoms existing in the $\mathrm{AA}-\mathrm{TiCl}_{3}$ catalyst. It is seen that all catalyst systems indicate two computer-simulated peaks in the region of $\mathrm{Ti}_{2 \mathrm{p} 3 / 2}$ spectra, which can be ascribed by the two kinds of Ti-species on the catalyst surface depending on the different levels of the coordination states of the surface titanium species. The plausible structures of these two kinds of surface titanium species are displayed in Scheme 1. A titanium species at a higher binding energy is assigned to the lower coordinated titanium species $\mathrm{Ti}^{+3}$ (a) with higher coordination vacancies whereas another titanium species at a lower binding energy is considered to be the higher coordinated titanium species $\mathrm{Ti}^{+3}(\mathrm{~b})$ with lower coordination vacancies. According to the literature (Arlman, 1966), at the surface of $\mathrm{TiCl}_{3}$ catalyst, two kinds of surface sites are possible: the first type has one chlorine vacancy and two loosely bound chlorine atoms and the second type consist of two chlorine vacancies with one loosely bound chlorine atom. Due to surface heterogeneity of the catalyst (Terano et al., 1997; Terano et al., 2000), titanium species may also remain on different surface locations and may exhibit different tendencies in the formation of active sites. Thus, low coordinated titanium species with two or three vacant sites can be possibly present at the edges and corners of the crystallites surface and highly coordinated titanium species with one vacant site or no vacant site at all known as the main plane, which forms $95 \%$ of the catalyst surface may be considered passive from the point of view of the polymerization process. An examination has been done (Kollar et al., 1968) with a polymerization process microscopically and found that two types of polymerization centers exist in $\mathrm{TiCl}_{3}$ drastically decreased in comparison to that of the titanium species obtained from the $\mathrm{AA}-\mathrm{TiCl}_{3}$ catalyst. TEA shows a more drastic decrease of the peak intensity of the $\mathrm{Ti}^{3+}(\mathrm{b})$ species and at the same time increased the peak of $\mathrm{Ti}^{3+}(\mathrm{a})$ species (Figure 1c) but DEAC did not show a big change (Figure 1b). From the XPS data analysis of these catalyst systems (Table I), it can be seen that after interaction with the cocatalyst the binding energy of the $\mathrm{Ti}^{3+}(\mathrm{b})$ species has decreased, which may be due to the association of the electron donating alkyl groups with the surface Ti-species (Terano et al., 1999). It can also be speculated that the weakly bonded surface chlorine atoms can be replaced by the electron donating ethyl group of the cocatalyst. XPS data analysis also shows that the atomic percentage of $\mathrm{Ti}^{3+}(\mathrm{b})$ species has decreased to about $70 \%$ after interaction with TEA and to about $32 \%$ with DAEC. This explanation is that TEA as a cocatalyst has remarkably transformed the higher coordinated titanium species $\mathrm{Ti}^{3+}$ (b) into a lower coordination state titanium species $\mathrm{Ti}^{3+}$ (a) due to its stronger reactivity than that of DEAC. Moreover, another explanation can be explored for the drastic decrease of surface atomic percentage of $\mathrm{Ti}^{3+}$ (b) species, which may be due to the extraction of surface dangling $\mathrm{Cl}$ by the effect of a cocatalyst. The extraction of surface dangling $\mathrm{Cl}$ is significantly affected by the effect of TEA, which shows a lower percentage of $\mathrm{Ti}^{3+}(\mathrm{b})$ species (only $18.84 \%$ ), while DEAC shows higher percentage of $\mathrm{Ti}^{3+}(\mathrm{b})$ species $(41.87 \%)$.

Here, it is worth-while using XPS observation to detect the difference in the titanium species in terms of coordination

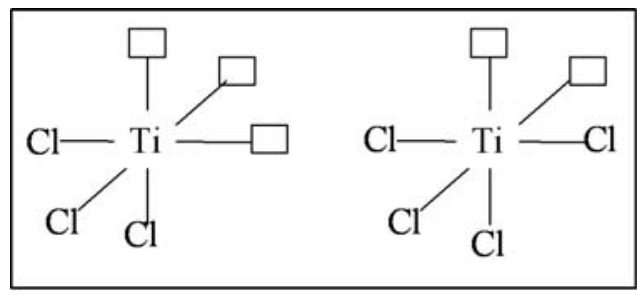

Group 1: Low coordinated $\mathrm{Ti}^{3+}(\mathrm{a})$

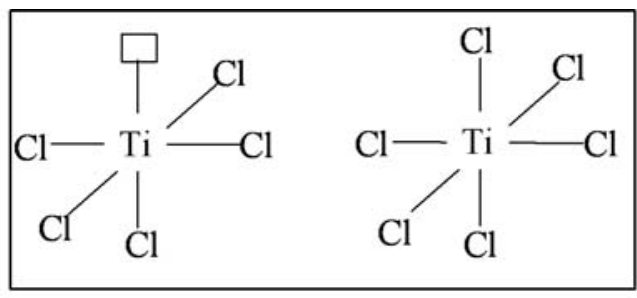

vacancy

\section{Scheme 1: Plausible structures of two types of titanium species on the catalyst surface.}

catalyst and another investigation has (John Boor, 1967) determined the coexistence of two different structures for active centers to account for the formation of both isotactic and atactic polymers.

From the Figure. 1, it can be seen that the used cocatalyst induced a change of chemical shift in the binding energy (BE) and a full width at half maximum (FWHM) intensity of the $\mathrm{Ti}_{2 \mathrm{p} 3 / 2}$ peak related to the different coordination state and atomic percentage. After interaction with the cocatalyst, the peak intensity of the higher coordinated $\mathrm{Ti}^{3+}(\mathrm{b})$ species has number produced by the reaction with various alkylaluminums (Terano et al., 1999) suggesting that the variation in the coordination state of the titanium species is closely related to the reactivity of the alkylaluminum. The binding energy $(\mathrm{BE})$ decreased, indicating the progress of the reduction of the titanium species on the catalyst. It is well known that surface Ti-species of heterogeneous Ziegler-Natta catalysts are first reduced and then alkylated by the effect of the cocatalyst. The FWHM of the Ti $2 p_{3 / 2}$ peaks of both Ti-species show different values after reacting with the cocatalyst, sug- 


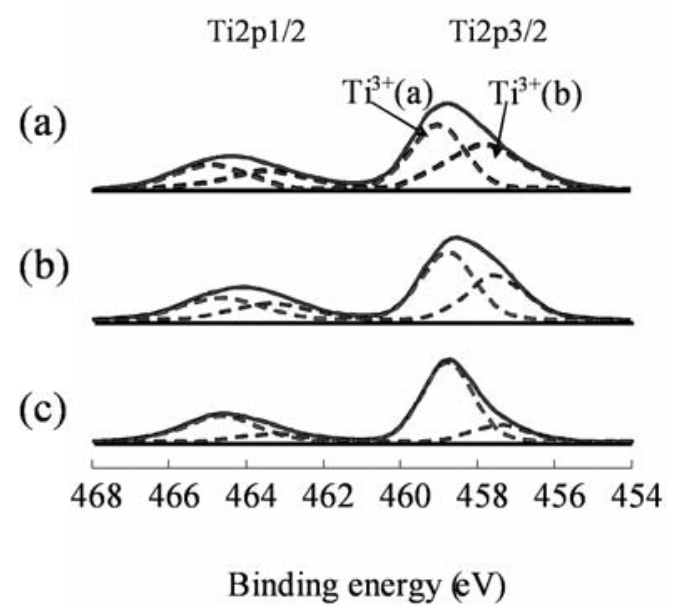

Fig. 1: The Ti 2p region of the XPS spectra. (a) $\mathrm{AA}-\mathrm{TiCl}_{3}$, (b) WG AA-TiCl 3 -DEAC, (c) AA-TiCl 3 -TEA. Solid line: instrumentally and dotted line : simulated

gesting the different chemical environment of the catalyst surface. In fact, however, the alkylaluminum cocatalyst interacts with the heterogeneous Ziegler-Natta catalyst through the ligand change of the surface Ti-species (Terano et al., 2002a; Terano et al., 2002b).

Figure 2(a) and Figure 2(b) show the deconvolution of GPC curves of polypropylene samples obtained from $\mathrm{AA}-\mathrm{TiCl}_{3}$ catalyst using TEA as cocatalyst at $60^{\circ} \mathrm{C}$ and $40^{\circ} \mathrm{C}$ respectively. Four types of Flory components (F1, F2, F3, and F4) were identified to describe the different active sites correlating to the different molecular weight distribution of deconvoluted GPC curves of polymer. It is notable that the microstructure analysis of the polypropylene samples were carried out by measuring the molecular weight and molecular weight distribution using GPC method and the curves were fitted by multiple Flory most probable distributions. The number of Flory peaks was correlated to the number of active sites and changes in the relative intensities of the different peaks were used as an indicator of the changes in active site distribution. It is well known that multiple active sites exist in heterogeneous Ziegler-Natta catalysts (Keii, 1990), including the $\mathrm{TiCl}_{4} / \mathrm{MgCl}_{2}$ based high-yield supported catalysts. In most cases, 3-6 types of active sites can be identified (Kissin, 1993; Fan et al., 1996) and each of them able to produce polymer with molecular weight and chain structure in different. According to this, it can be said that higher coordinated surface titanium species is considered to be higher molecular weight Flory component of active sites, which produces higher molecular weight polymer chain. The average molecular weights of Flory components differ quite significantly from site to site. As a result, different active sites produce polymer molecules with molecular weight values in the broad ranges.

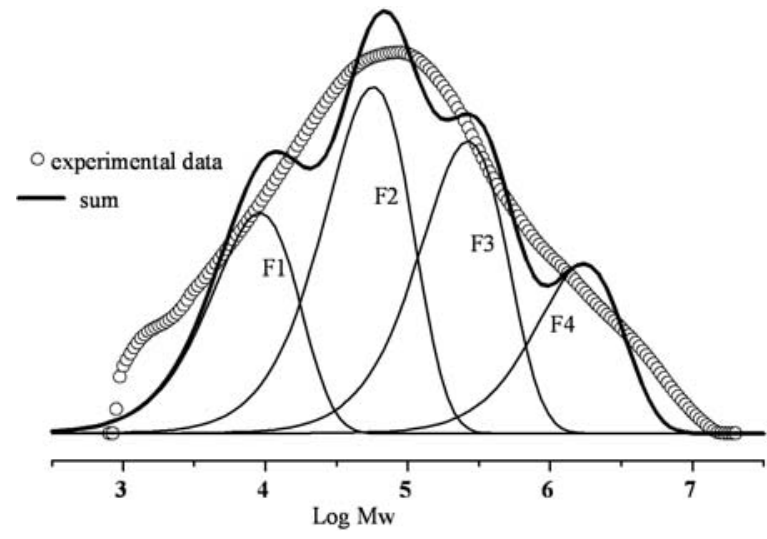

Fig. 2(a): GPC curves and Flory components of polypropylene prepared with $\mathrm{AA}-\mathrm{TiCl}_{3}$ catalyst using TEA as cocatalyst at $60^{\circ} \mathrm{C}$

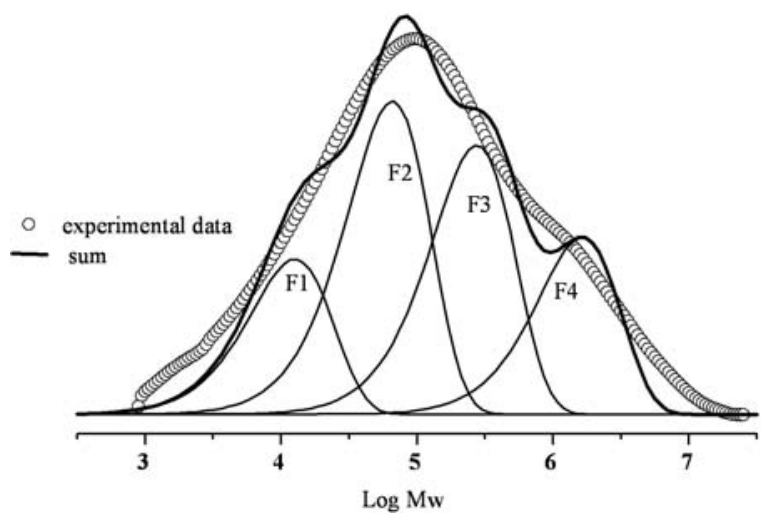

Fig. 2(b): GPC curves and Flory components of polypropylene prepared with $\mathrm{AA}-\mathrm{TiCl}_{3}$ catalyst using $\mathrm{TEA}$ as cocatalyst at $40^{\circ} \mathrm{C}$

Figure 3(a) and Figure 3(b) show the GPC curves of polypropylene samples produced with $\mathrm{AA}-\mathrm{TiCl}_{3}$ catalyst using DEAC as cocatalyst at $60^{\circ} \mathrm{C}$ and $40^{\circ} \mathrm{C}$, respectively and their deconvolution results based on multiple peaks of Flory components. It is seen that higher MW peaks are assigned to the higher coordination surface Ti species with higher isospecificity of active sites. The broad MWD of polypropylene prepared with $\mathrm{MgCl}_{2} / \mathrm{TiCl}_{4} / \mathrm{TEA}$ catalysts can be represented by several Flory components (Kissin, 2001). The procedure for the resolution of complex GPC curves into those of the Flory components were required to describe adequately the MWD. Meanwhile, all the peaks were shifted from lower MW to higher MW after replacing TEA with DEAC. It is due to having higher number of $\mathrm{Ti}^{+3}(\mathrm{~b})$ species. It means that different active sites respond to the cocatalyst quite differently. 


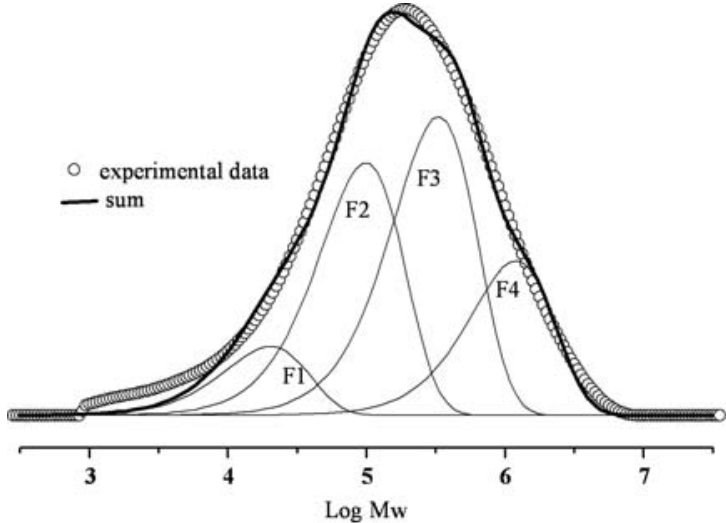

Fig. 3(a): GPC curves and Flory components of polypropylene prepared with $\mathrm{AA}-\mathrm{TiCl}_{3}$ catalyst using DEAC as cocatalyst at $60^{\circ} \mathrm{C}$

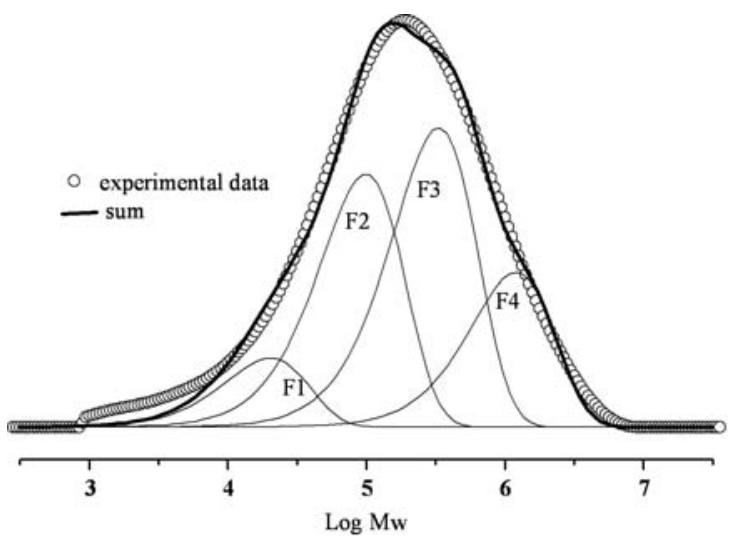

Fig. 3(b): GPC curves and Flory components of polypropylene prepared with $\mathrm{AA}-\mathrm{TiCl}_{3}$ catalyst using DEAC as cocatalyst at $40^{\circ} \mathrm{C}$

The average molecular weight decrease, presumably because of an increased probability of chain termination reactions at higher temperature and types of cocatalysts. Therefore, the replacement of TEA as a cocatalyst with DEAC usually results in an increase in the polymer molecular weight. This means that the molecular weights of all Flory components are increased in the polymer with DEAC. From the comparison between Figure 2 and Figure 3, it can be said that the reason for the broad molecular weight distribution of polypropylene produced with TEA is mainly existence of various active sites mainly higher number of $\mathrm{Ti}^{+3}$ (a) species, which indicate preferential rate of propagation, chain termination and chain transfer rate constants. The key concept to interprete these phenomena in relation to the cocatalyst concentrations is assuming the existence of at least two kinds of titanium species. The influence of deactivation of the active sites due to the over reduction is the higher the reducing power of the cocatlyst, the greater the deactivation (Terano et al., 1998). Thus it can be assumed that a part of the titanium species might be activated easily by the reduction of TEA to generate active sites having easy deactive feature. On the other hand, the catalyst system with DEAC produces narrow ranges molecular weight distribution of polypropylene (Figure 3 ) due to the formation of active sites having lower reduction power and chain termination and transfer ability during polymerization. It has been known for a long time that the replacement of TEA as a cocatalyst with DEAC usually depresses not only the activity but also results in an increase in the polymer molecular weight (Busico et al., 1997; McKnight and Waymouth, 1998; McKnight et al., 1997).

Figure 2 and Figure 3 show another comparison of GPC deconvoluted curves at different temperatures with TEA and DEAC respectively. Decreasing the temperature led to the evolution of mutiple peaks toward the high molecular weight region in the case of both TEA and DEAC. Lower temperature induces the formation of polypropylene with higher molecular weight is a similar tendency as it was obtained from the effect of cocatalyst types. It is suggested that the active sites giving higher molecular weight polymer exist preferentially and the chain transfer reaction is depressed at lower temperature. It has been reported (Kissin, 2001) that the fractions of Flory components with the highest molecular weight significantly decrease with the increase of temperature, which enhances the probability of chain transfer reaction and causes the decreases the average molecular weight with temperature.

\section{Conclusion}

The multiplicity of active site in Ti-based Ziegler-Natta catalyst explains the correlation between the nature of active sites and microstructure of polymer chains existing in the polypropylene sample. The molecular weight distributions of polypropylene obtained were sensitive to types of cocatalyst and polymerization temperature. Higher molecular weight Flory components of active sites originated from the higher coordinated surface titanium species resemble higher isospecific active sites, which replicates the polymerization and produced polymer with higher molecular weight. Lower polymerization temperature and the use of DEAC as a cocatalyst resulted the higher molecular weight polymer due to lower deactivating ability and a little chain transfer and termination reactions. A comparison of GPC deconvolution results based on the molecular weight distribution of the polymer with the simulation of XPS data based on the coordination states of surface Ti-species provide complimentary information on the multiplicity of active site on the heterogeneous Ziegler-Natta catalyst. Such an analysis has signifi- 
cantly improved our understanding of the catalyst behavior and provides additional tools for catalyst and process control.

\section{Acknowledgement}

The author is grateful to Japan Advanced Institute of Science and Technology for kind cooperation regarding this work.

\section{References}

Arlman E. J. (1964a). Ziegler-Natta catalysis II. Surface structure of layer-lattice transition metal chlorides. $J$. Catal. 3: 89-98.

Arlman E. J. (1964b). Ziegler-Natta catalysis III. Stereispecific polymerization of proene with $\mathrm{TiCl}_{3}$ $\mathrm{AlEt}_{3}$ catalyst system. J. Catal. 3: 99-104.

Arlman E. J. (1966). Ziegler-Natta Catalysis IV. The Stereospecificity in the Polymerization of Olefins and Conjugated Dienes in Relation to the Crystal Structure of $\mathrm{TiCl}_{3}$. J. Catl. 5: 178-189.

Boor J. (1971). Ziegler polymerization of olefins. IX. Donor effects in metal alkyl-free and Ziegler-Type stereospecific catalysts. J. Polym. Sci. part A-1 vol. 9: 617-628.

Boor J. Jr. (1979). Ziegler-Natta catalysts and Polymerizations. Academic press, New York.

Busico V., Chipullo R., Monaco G. and Vacatello M. (1997). Macromolecules 30: 6251.

Busico V., Cavallo L., Guerra G., Vacatello M. and Venditto V. (1999). High resolution ${ }^{13} \mathrm{C}$-NMR configurational analysis of polypropylene made with $\mathrm{MgCl}_{2}$ supported Ziegler-Natta catalysts. Macromolecules 32: 41734182.

Busico V. and Chipulo R. (2001). Microstructure of Polypropylene. Prog. Polym. Sc., 26: 443-533.

Corradini P., Busico V., Cavallo L., Guerra G., Vacatello M. and Venditto V. (1992). A reinvestigation of beta titanium trichloride- Catalytic activity in propene polymerization. Euo. Poym. J., 28: 519-523.

Corradini P., Busico V., Cavallo L., Guerra G., Vacatello M. and Venditto V. (1993). On the mechanism of syndiotactic propene polymerization in the presence of $\mathrm{Ti}-$ based heterogeneous Ziegler-Natta catalysts. Makromol. Symp., 66: 11.

Corradini P., Busico V., Cavallo L., Guerra G., Vacatello M. and Venditto V. (1994). Steric control in Ziegler-Natta catalysts: An analysis of nonbonded interactions at model catalytic sites. Stud. Sur. Sc. Catal., 89: 21.
Debuquoit C. M., Riga J. and Verbist J. J. (1983). J. Chem. Phys. 26: 79.

Debuquoit C. M., Riga J. and Verbist J. J. (1987). Inorg. Chem. 26: 1212.

Fan Z. Q., Feng L. X. and Yang S. L. (1996). J. Polym. Sci. Part 4: Polym Chem. 34: 3329.

Fan Z. Q., Yang K., Deng H. Y. and Jiang X. (2003). Structure and properties of polypropylene/poly(ethylene-co-propylene) in-situ blends synthesized by spherical Ziegler-Natta catalyst. Polymer 42: 5559-5566.

Galli P., Barbe P. C., Guidetti G. P., Zannetti R., Martorana A., Marigo A., Bargozza M. and Fischera A. (1984). The activation of $\mathrm{MgCl}_{2}$-supported ziegler-Natta catalysts: A structural investigation. Eur. Polym. J. Vol. 19: 19-24.

Giannini U. (1981). Makromol. Chem. Suppl. 5: 216.

Hasan A. T. M. K., Liu B. and Terano M. (2005). Effects of Various Preparation and Polymerization Procedures on the Isospecific Nature of $\mathrm{TiCl}_{3}$-Based Polypropylene Catalysts. Polymer Bulletin, 54: 225-236.

Kashiwa N. and Yoshiteke J. (1983). Propylene polymerization with high activity catalyst system: $\mathrm{MgCl}_{2} / \mathrm{TiCl}_{4}$ $\mathrm{Al}\left(\mathrm{C}_{2} \mathrm{H}_{5}\right)_{3}$ Makromol. Chem., Rapid Comun.4: 41-44.

Kashiwa N. and Yoshiteke J. (1984). Makromol. Chem. 185: 1133.

Keii T. (1990). Transition metals and organometallics as catalysis for olefin polymerization, Stud. Surf. Sci. Catal. 56: 1 .

Kim S. H. and Somorjai G. A. (1983). Preparation of a model Ziegler-Natta catalyst: Surface science studies of magnesium chloride thin film deposited on gold and its interaction with titanium chloride. J. Chem. Phys. 79: 26.

Kim S. H. and Somorjai G. A. (2000). Model Ziegler-Natta Polymerization Catalysts Fabricated by Reactions of $\mathrm{Mg}$ Metal and $\mathrm{TiCl}_{4}$ : Film Structure, Composition, and Deposition Kinetics. .J. Phys. Chem. B 104: 55195526.

Kim S. H. and Somorjai G. A. (2001). Characterization of the Ziegler-Natta olefin polymerization system: surface science studies on model catalysts. Surf. Interface Anal. 31: 701-710.

Kim S. H. and Somorjai G. A. (2001). Correlation between Catalyst Surface Structure and Polypropylene Tacticity 
in Ziegler-Natta Polymerization System. J. Phys. Chem. B 105: 3922-3927.

Kissin Y. V. (1993). Makromol Chem. Macromol Symp., 66: 83.

Kissin Y .V. (1995). Molecular Weight Distributions of Linear Polymers: Detailed Analysis from GPC Data. $J$. Polym. Sci. Part A: Polym. Chem 33: 227-237.

Kissin Y. V. (2001). Main Kinetic Features of Ethylene Polymerization Reactions with Heterogeneous ZieglerNatta Catalysts in the Light of a Multicenter Reaction Mechanism. J. Polym. Sci.: Part A: Polym Chem. 39: 1681-1695.

Kissin Y. V. (2003). Multicenter Nature of Titanium-Based Ziegler-Natta Catalysts: Comparison of Ethylene and Propylene Polymerization Reactions. J. Polym. Sci.: Part A: Polym. Chem.41: 1745-1758.

Kissin Y. V. (2005). Multi-Center Nature of Heterogeneous Ziegler-Natta Catalysts: TREF Confirmation. J. Polym. Sci. part A: Poly. Chem. 43: 4351-4362.

Magni E. and Somorjai G. A. (1997). Surface science study of model Ziegler-Natta catalysts. Eur. Con. Sur. Sci. 377: 824-827.

McKnight A. L., Masood M. A., Waymouth R. M. and Strauss D. A. (1997). Organometallics, 16: 2879.

McKnight A. L. and Waymouth R. M. (1998). Chem. Rev. 98: 2587.

Kollar L., Simon A. and Kallo A. (1968). Study of ZieglerNatta Catalysts. Part III. Effect of the structure of titanium trichloride on the polymerization of propylene. $J$. Polym. Sci.: Part A-1 6: 937-943.

Somorjai G. A., Enrico M. and Koraney T. (1999). Surface science approach to the preparation and characterization of model Ziegler-Natta heterogeenous polymerization catalysts. Catal. J. 7: 179-185.

Terano M., Mori H. and Yoshitome M. (1997). Investigation on fine-grain $\mathrm{MgCl}_{2}$-supported Ziegler catalyst by stopped-flow propene polymerization: model for the formation of active sites induced by catalyst fragmentation during polymerization. Macromol. Chem. Phys. 198: $3207-3214$.
Terano M., Mori H. and Ohnishi K. (1998). Multiplicity of molecular weight distribution of polyethylene produced with modified-polypropylene-supported Ziegler catalyst systems. Macromol. Chem. Phys. 199: 393399.

Terano M., Mori H., Hasebe K. (1999). Variation in oxidation state of titanium species on $\mathrm{MgCl}_{2}$-supported Ziegler-Natta catalyst and its correlation with kinetic behavior for propylene polymerization. Polymer, 40: 1389-1394.

Terano M., Mori H. and Hasebe K. (1999). XPS study of the interaction of titanium species with internal electron donors on $\mathrm{MgCl}_{2}$-supported Ziegler catalysts. J. Mol. cat. A: Chem. 140: 165-172.

Terano M., Mori H. and Yoshitome M. (2000). Microstructural heterogeneities of 1,5 hexadiene obtained by stopped-flow and conventional methods: correlation to plural active sites for propylene on $\mathrm{MgCl}_{2}$-supported Ziegler catalysts. Macromol. Chem. Phys.201: 543-551.

Terano M., Liu B. and Matsuoka H. (2001). Kinetic Evaluation of various isospecific active sites on magnesium chloride supported ziegler catalysts. Macromol. Symp. 193: 71-80.

Terano M., Liu B., Nitta T. and Nakatani H. (2002). precise arguments on the distribution of stereospecific active sites on magnesium chloride supported Ziegler-Natta catalysts. Macromol. Symp. 213: 7-18.

Terano M., Nitta T., Liu B. and Nakatani H. (2002a). Formation, deactivation and transformation of stereospecific active sites on $\mathrm{TiCl}_{4} /$ dibutylphthalate $/ \mathrm{Mg}(\mathrm{OEt})_{2}$ catalyst induced by short time reaction with Al-alkyl cocatalyst. J. Mol. Catal. A: Chem. 180: 2534.

Terano M., Liu B., Nitta T. and Nakatani H. (2002b) Specific roles of Al-Alkyl Cocatalyst in the Origin of Isospecificity of Active Sites on Donor-Free $\mathrm{TiCl}_{4} / \mathrm{MgCl}_{2}$ Ziegler-Natta Catalyst. Macromol. Chem. Phys. 203: 2412-2421.

Received: January, 19, 2010;

Accepted : February 24, 2011 